\title{
Analysis of Stress, Anxiety and Depression of Children During COVID-19
}

\author{
${ }^{1}$ Shawni Dutta and ${ }^{2}$ Prof. Samir Kumar Bandyopadhyay \\ ${ }^{1}$ Department of Computer Science, The Bhawanipur Education Society College, Kolkata, \\ India. \\ ${ }^{2}$ Academic Advisor, The Bhawanipur Education Society College, Kolkata, India.
}

\section{Abstract}

Coronavirus is believed to have originated from a wet market in Wuhan, China, and has spread all over the world, resulting in a large number of hospitalizations and deaths. Social scientists are just beginning to understand its consequences on human behavior. One policy that public health officials put in place to help stop the spread of the virus were stay-at-home/shelter-inplace lockdown-style orders. Schools, Colleges and Universities across the country have now been shut down till now due to Covid-19. Some Governments in India impose lockdown to reduce the crises created by this unknown virus. It is now difficult to make final assessments by school, school leaving examinations and entrance tests for undergraduate and post-graduate courses. This disruption implies for students across the socio-economic spectrum, both in terms of learning outcomes, food and economic security. Here the aim is to discuss the implications of lockdown-induced in schools in both urban and rural areas in India.

The whole world implemented a nationwide lockdown to curb the transmission of the virus. A survey was over Five hundred families to complete a questionnaire with questions around symptoms of depression, anxiety, stress, and family affluence. The humans who do not have enough supplies to sustain the lockdown were most affected Families with affluence were found to be negatively correlated with stress, anxiety, and depression. Stress, anxiety, and depression more than others are seen in students and healthcare professionals. The main aim of the paper is to find out how symptoms of depression, anxiety and stress on parents due to COVID-19.

\section{Key-Words: COVID-19, Stress, Mental Anxiety, Depression, Children and Attributes Introduction}

COVID-19 made a diverse range of potential effects of the crisis, such as reduction of stress, improved sleep and relaxation, loss of social pressure, more time to think and improved affect. 
Both positive and negative responses of children and families to this crisis should be understand the impact on modern daily life routines and environments due to COVID-19.

This has a positive effect on protecting health, especially for the elderly and ill people. Children, adolescents and their parents are usually at a much lower risk for severe illness, even if there have been rare deaths in this age range as well. More of children and adolescents have faced the effects of school closures. In addition, most other social and out-of-home activities for children and adolescents have been canceled. They no longer enjoy positive interactions with their sport coaches, music teachers, friends and peers. Children and their families have to share a restricted space at home with limited resources and have to change their daily life and routines to cope with numerous new challenges.

Children are supposed to get home schooling, supervised by parents. However, some parents are expected to work as much as possible at home office or, due to the nature of their job, are confronted with daycare problems. Support and the help of grandparents and other family members fall away, as they should avoid contact. All family members struggle with their own anxieties in this situation and for many families, economic pressure further increases stress. When a family member dies, the child has to deal with their grief. Quite often, a combination of challenges clusters in families with limited space, job loss, and other known risk factors such as mental illness/disabilities of family members or single parenting.

Recruitment is not possible because of home working and the difficulty of ensuring equity of opportunity. On the positive side, we see an acceleration in switching to online training and supervision, development of e-learning. In the long term, child mental health is the basis for future adult mental health which is closely associated with general health and is, thus, related to productivity and well-being in our society. Although measures that aim for "social distancing" are important to protect the health of our society, Effective alternatives for school closures may be "physical distancing" measures. It is basically to keep students in classrooms and to decrease the number of students per class and to increase space between students.

\section{Review Works}

Around the globe Covid-19 has caused significant distress. It has caused serious damage to public mental health apart from infection from corona virus It is known to everybody that lockdowns and quarantines are essential to suppressing COVID-1 [ 1]. All persons may leave their residences only for essential activities or to provide or perform essential functions or to operate essential businesses. All businesses (except for essential businesses) are stopped. If employees and contractors can work from their own residence, then businesses may continue to operate. Essential businesses should maintain social distancing of $6 \mathrm{ft}$. between employees 
and the general public [2]. Religious institutions must limit in-person staff to 10 people or less when preparing video or teleconference services and must follow $6 \mathrm{ft}$. social distancing [3].

Due to Covid-19 it has brought about many unknowns and thereby causing social stigmatization towards groups of people, those infected and their family [4]. Children are affected in the social or educational domain. These situations have serious health consequences as well as a risk of late presentation of corona patient to the hospital [5]. Every disaster has its learning opportunities and so does the current Covid-19 crisis [6]. Children are now more time to spend with their parents. School closures gave them awareness that school and education is an opportunity. Parents get more times to educate their children on health responsibilities and involve children in washing hands at regular interval. Parents are forced to rely on their own skills to manage children with mild symptoms of any disease and this might increase parents' self-confidence in maintaining the health of their children.

Proposed Method

A study has been made over children of families in West Bengal, Kolkata, India, on the Attributes- Stress, Mental Anxiety, Loneliness, Home quarantine, Single Child or more than one child, Depression, Closure of Schools, Social pressure and Fear for family Illness for the effect due to COVID-19. During the study it is fond that the entire studies will be considered on the three attributes- Stress, Mental Anxiety and Depression. The study is made for four months from April 2020 to July 2020. The entire processes are described from Figure 1 to Figure 5 and Table 1 to Table 6 . The analysis shows that the increase of selected attributes is evident from final result.

\begin{tabular}{|r|r|r|r|r|}
\hline April & Cities & Urban Areas & Rural Areas & \\
\hline 5 & 10 & 5 & 4 & \\
\hline 12 & 12 & 18 & 20 & \\
\hline 18 & 30 & 10 & 15 & \\
\hline 23 & 25 & 20 & 30 & \\
\hline 28 & 11 & 17 & 19 & \\
\hline 30 & 4 & 14 & 9 & \\
\hline & 82 & 84 & 97 & 263 \\
\hline
\end{tabular}

Table 1 Attended Families in April 2020 


\section{Total Families $=263$}

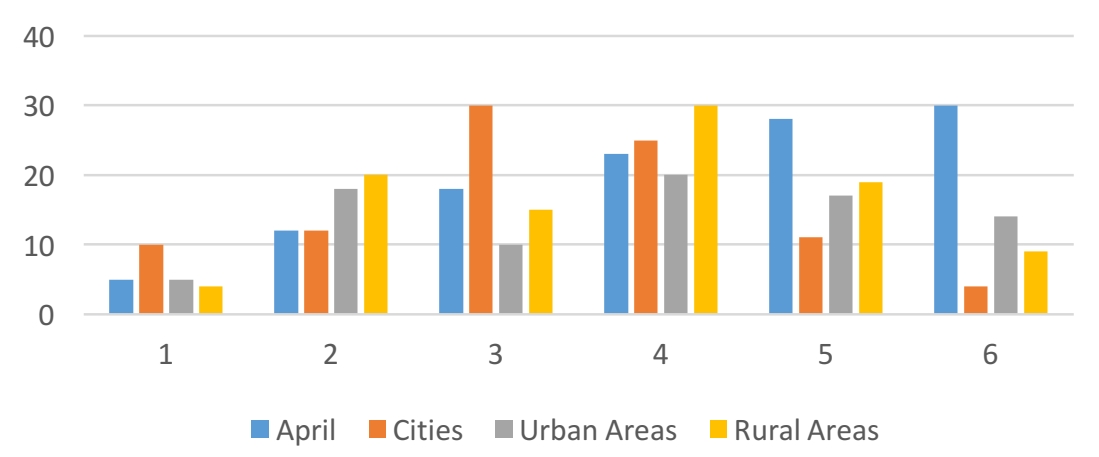

Figure 1 Graph shows Attended Families in the Month of April 2020

\begin{tabular}{|r|r|r|r|r|}
\hline May & Cities & & Urban Areas & Rural Areas \\
\hline 10 & 6 & 10 & 8 & \\
\hline 15 & 10 & 5 & 5 & \\
\hline 20 & 9 & 4 & 7 & \\
\hline 27 & 18 & 10 & 7 & \\
\hline 31 & 11 & 15 & 6 & \\
\hline 31 & 7 & 14 & 11 & 157 \\
\hline & 55 & 58 & 44 & \\
\hline
\end{tabular}

Table 2 Attended Families in May 2020

Total Families $=157$

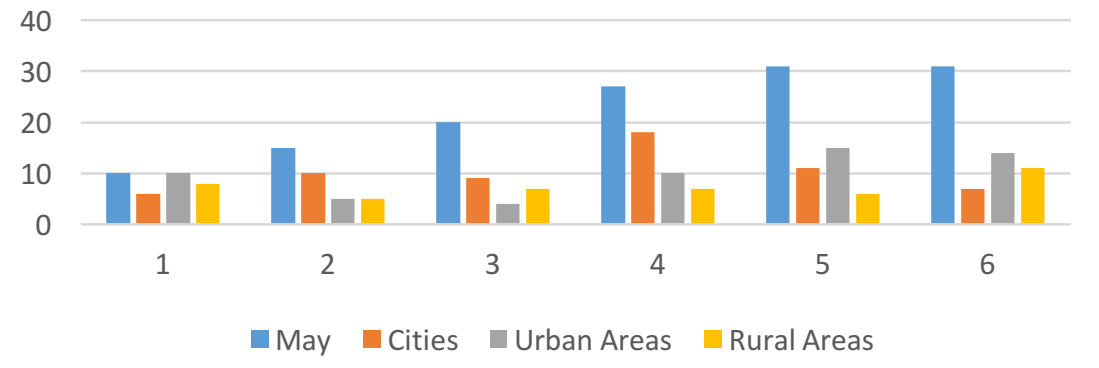

Figure 2 Graph shows Attended Families in the Month of May 2020

\begin{tabular}{|r|r|r|r|r|}
\hline June & Cities & & Urban Areas & Rural Areas \\
\hline 15 & 6 & 10 & 8 & \\
\hline 10 & 10 & 5 & 5 & \\
\hline 25 & 9 & 4 & 7 & \\
\hline 27 & 18 & 10 & 7 & \\
\hline 31 & 37 & 29 & 27 & 124 \\
\hline
\end{tabular}

Table 3 Attended Families in June 2020 


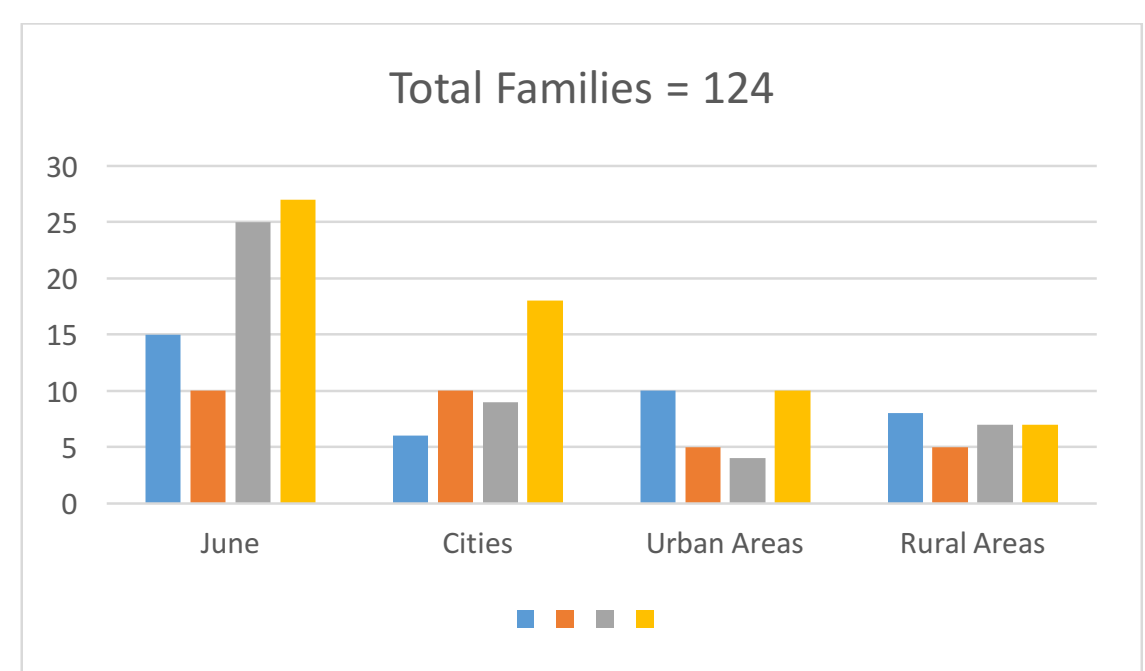

Figure 3 Graph shows Attended Families in the Month of June 2020

\begin{tabular}{|r|r|r|r|r|}
\hline July & Cities & & Urban Areas & Rural Areas \\
\hline 15 & 6 & 10 & 8 & \\
\hline 10 & 10 & 5 & 5 & \\
\hline 25 & 9 & 4 & 7 & \\
\hline 27 & 18 & 10 & 7 & \\
\hline 31 & 37 & 29 & 27 & \\
\hline & 80 & 58 & 54 & 192 \\
\hline
\end{tabular}

Table 4 Attended Families in July 2020

Total Families $=192$

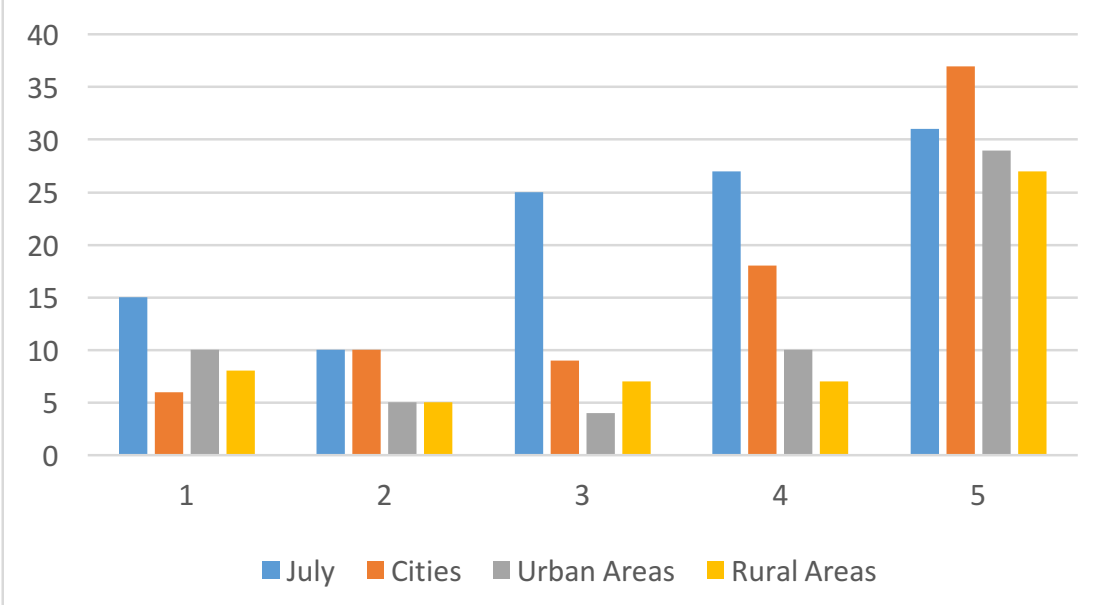

Figure 4 Graph shows Attended Families in the Month of July 2020

\begin{tabular}{|r|r|r|r|r|}
\hline 263 & 157 & 124 & 192 & 736 \\
\hline
\end{tabular}

Table 5 Total Collected Families from April 2020 to July 2020 and Total attended Families is 736 


\begin{tabular}{|r|l|r|r|r|}
\hline Families & Month & Stress & Anxiety & Depression \\
\hline 263 & April & 100 & 90 & 73 \\
\hline 157 & May & 40 & 60 & 57 \\
\hline 124 & June & 24 & 40 & 60 \\
\hline 192 & July & 80 & 100 & 12 \\
\hline 736 & & 244 & 290 & 202 \\
\hline
\end{tabular}

Table 6 Stress, Anxiety and Depression during four Months

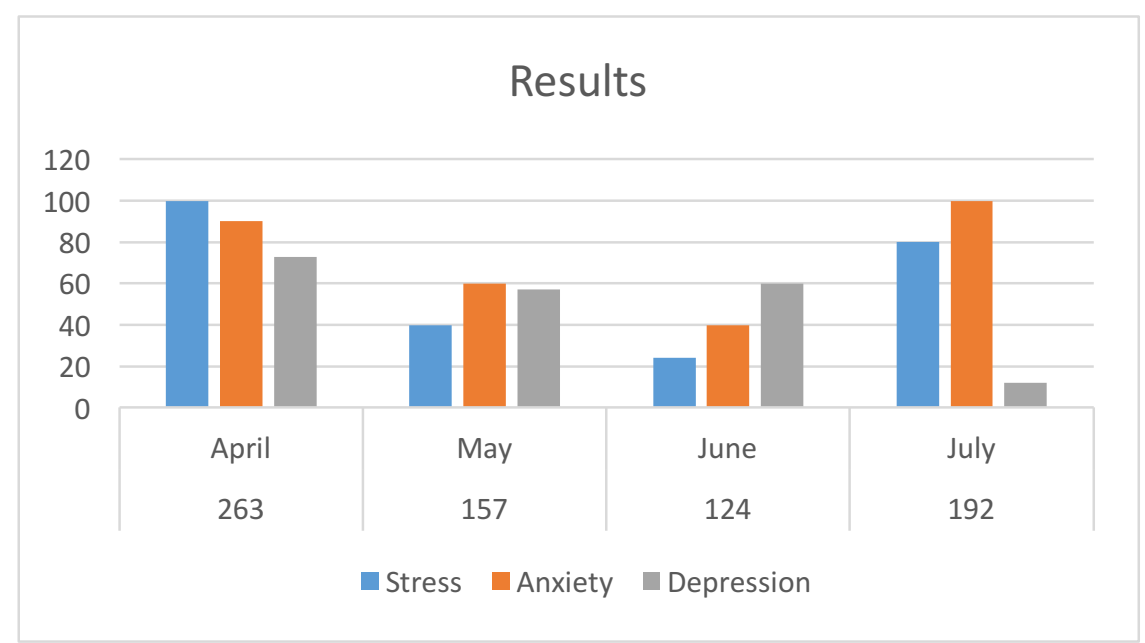

Figure 5 Final Result

\section{Conclusions}

The depression is viewed as a state of disinterest. It is viewed as a state of disinterest in daily activities. Children are facing a pandemic in fear of the unknown disease, coronavirus, making them anxious, stressed and depressed. The region is divided into Cities, Urban Areas and Rural Areas. Children are classified from age group 4 to 12 years. The aim of the paper is to study effects of three attributes on the children.

\section{References}

1. Campbell AM (2020) An increasing risk of family violence during the Covid-19 pandemic: strengthening community collaborations to save lives. Forensic Sci. Int. Reports 2:100089 https:/www.ncbi.nlm. nih.gov/pmc/articles/PMC7152912/.

2. Federal Aviation Administration. Eastern Airlines Flight 401, Lockheed Model L1011, N310EA [Internet]. Lessons Learned. 1972 [cited 2020 Apr 17]. Available from: https://lessonslearned. faa.gov/llmain.cfm? TabID=3\&LLID=8. 
3. Ministère de L'intérieur (2020) Communiqué de presse conjoint du 22 avril 2020 Enfance en danger: Gouvernement mobilisé [Internet]. [cited 2020 Apr 23].

4. UNESCO. COVID-19 Educational Disruption and Response [Internet]. [cited 2020 Apr 20]. Available from: https://en.unesco. org/covid19/education response.

5. UNICEF (2020) Social Stigma associated with COVID-19: A guide to preventing and addressing social stigma [Internet\}. Available from: https://www.unicef.org/documents/socialstigma-associated-coronavirus-disease-covid-19.

6. Wang Y, Zhou CC, Shu R, Zou J (2020) Oral health Management of Children during the epidemic period of coronavirus disease 2019. Sichuan da xue xue bao. Yi xue ban (in chinese). Journal of Sichuan University. Medical Science Edition, pp 151-1544. 